\title{
Varied presentations of Wilson's Disease in Childhood - A Case Series and Review of Literature
}

\section{Richa Chaudhary, Sham Lohiya, Keta Vagha and Sachin Damke}

Department of Paediatrics, Jawaharlal Nehru Medical College, Datta Meghe Institute of Medical Sciences (DMIMSDU), Sawangi (Meghe), Wardha, Maharashtra, India

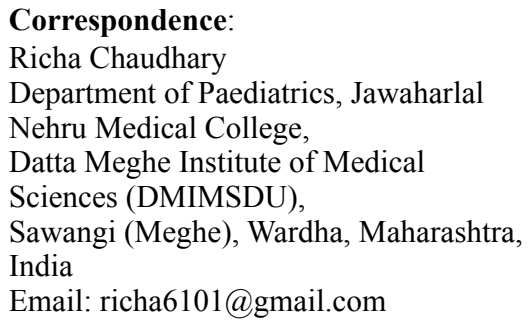

Email: richa6101@gmail.com

DOI: $10.3126 /$ jnps.v41i2.31904

Submitted on: 2020-06-11

Accepted on: 2020-10-04

Acknowledgements: None

Funding: Nil

Conflict of Interest: None declared

Permission from IRB: Yes
To cite this article: Chaudhary R, Lohiya $\mathrm{S}$, Vagha K, Damke S. Varied presentations of Wilson's Disease in Childhood - A Case Series and Review of Literature. J Nepal Paediatr Soc. 2021;41(2):258-65.

\begin{abstract}
Wilson's disease is an autosomal recessive disorder of copper metabolism associated with deposition of copper in various organs including the heart and the brain. Hepatic manifestations are the commonest but various extrahepatic manifestations are known which include neuropsychiatric features, haemolytic anaemia, arthropathy etc. Knowledge of all these manifestations result in early clinical suspicion and the diagnosis of Wilson's disease is confirmed by increased urinary copper levels and decreased serum cerruloplasmin level. Other tests which can be done to confirm the diagnosis include molecular testing and liver copper estimation. Once diagnosed, Wilson's disease should be treated with chelating agents (e.g. d-penicillamine) and restriction of dietary copper. Timely treatment with zinc acetate or d-penicillamine prevents progression of the disease in asymptomatic children. Adequate chelation also results in good overall prognosis even in symptomatic children. Here we report a case series of nine children with different manifestations of Wilson's disease throwing more light on the subject.
\end{abstract}

Keywords: d-penicillamine; different manifestations; Wilson's disease

This work is licensed under creative common attribution 3.0 license

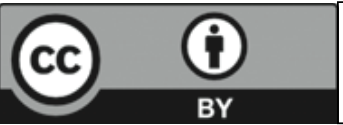

This work is licensed under creative com 


\section{INTRODUCTION}

Wilson's disease (WD) is an autosomal recessive disorder and is caused by mutation in ATP7B gene which is responsible for copper excretion into the bile. ${ }^{1}$ Copper is transported in the periphery bound to ceruloplasmin which is produced with the help of ATP7B. Thus mutation in ATP7B gene results in decreased synthesis of copper bound ceruloplasmin and impaired excretion of copper. Due to impaired excretion, there is accumulation of copper in the liver from early infancy which eventually results in copper overload and hence it starts accumulating in other organs such as nervous system, cornea, kidneys and heart. ${ }^{2,3}$ Children predominantly present with hepatic involvement which can range from asymptomatic with only biochemical abnormalities to acute liver failure. Chronic liver disease with evidence of cirrhosis may be the presentation in many paediatric patients. Rarely isolated splenomegaly may be the only presentation where portal hypertension and cirrhosis is diagnosed later while investigating the child with splenomegaly. Important extrahepatic manifestations include neuropsychiatric manifestations, Coombs - negative haemolytic anaemia, certain renal abnormalities (aminoaciduria and nephrolithiasis), skeletal abnormalities such as premature osteoporosis and arthritis, cardiomyopathy, dysrhythmias and pancreatitis. ${ }^{2}$ Though these manifestations are rare in paediatric age group practitioners should be aware of these presentations of WD in children with or without liver involvement so that early institution of the available therapy results in better prognosis. We here report a case series of nine children with Wilson's disease with varied clinical features which will further throw light on the subject and will guide the treating paediatrician in early diagnosis and treatment of children with Wilson's disease.

\section{Acute Liver Failure as the Presentation of Wilson's disease}

\section{Case 1}

A 10 - year - old female child was admitted with the complaints of abdominal distension and yellowish discoloration of eyes and urine for last one month. The parents complained that the patient's condition has further deteriorated for last five days with breathlessness and irrelevant talking for last one day. On examination patient was drowsy, vitals were stable and she had pallor and deep icterus. Abdomen was distended with flanks full, liver was palpable $6 \mathrm{~cm}$ below right coastal margin, firm with regular margins and was tender. Shifting dullness was present. Other systemic examination was within normal limits. Patient was shifted to Paediatric Intensive Care Unit (PICU) and treatment was started on lines of acute hepatic failure. Her investigations showed haemoglobin of $7.7 \mathrm{gm} / \mathrm{dl}$, SGOT- $436 \mathrm{IU} / \mathrm{L}$, SGPT- $254 \mathrm{IU} / \mathrm{L}$, Alkaline phosphatase (ALP)- 236 IU/L, Total serum bilirubin level (TSB) - $28 \mathrm{mg} / \mathrm{dl}$ (direct $15.2 \mathrm{mg} / \mathrm{dl}$ ), and INR of 3.25 . Her corrected reticulocyte count was 2.3 and Direct Coombs test (DCT) was negative. Hepatitis B surface antigen (HBs) was done and it was negative and on ophthalmic examination Kayser-Fleischer (KF) ring was not seen. 24-hour urinary Copper was 1468.14 mcg and serum ceruloplasmin was $11 \mathrm{mg} / \mathrm{dl}$ hence patient was labeled as Wilson's disease. Over the course of time patient deteriorated further and was ventilated. Later patient died on day fifth of admission.

\section{Acute on Chronic Liver Failure \\ Case 2}

A five year old male child was admitted with complaints of abdominal distension and yellowish discolouration of eyes for two months. Patient was admitted for the same complaints in other health facility eight months back and was then diagnosed as having Wilson's disease on the basis of decreased serum ceruloplasmin and increased 24hour urinary copper. Slit lamp examination was done which revealed KF ring in both the eyes. He was then started on d-penicillamine but had stopped the drug since last three months. He presented to us with history of difficulty in breathing and increased distension of abdomen since past five days. There was history of altered sensorium with generalised tonic-clonic convulsions involving all four limbs for last one day. On examination child was unconscious, with gasping type of respiration. $\mathrm{He}$ was immediately intubated and shifted to PICU and started on mechanical ventilatory support. His BP was $110 / 60 \mathrm{~mm}$ of $\mathrm{Hg}$, pulse rate was $110 / \mathrm{min}$ and all peripheral pulses were well felt. On per abdomen examination there was distension with 
shiny skin and visible veins over the abdomen and fluid thrill was present. Patient's investigations revealed Hb- 8.2 gm/dl, SGOT - 112 IU/L, SGPT $228 \mathrm{IU} / \mathrm{L}, \mathrm{TSB}-42 \mathrm{mg} / \mathrm{dl}$ (direct-30 mg/dl), ALP $568 \mathrm{IU} / \mathrm{L}$, serum albumin was $1.9 \mathrm{gm} / \mathrm{dl}$ and INR 1.8. Treatment was started on lines of acute hepatic failure. Patient died after six days of PICU stay.

\section{Case 3}

A 10-year-old boy presented to us with the history of fever for last 15 days, breathing difficulty for last few days. He had history of jaundice and abdominal distension for last three months for which he had shown in the other hospital where he was diagnosed as having Wilson's disease as his 24 urinary copper was increased and serum ceruloplasmin level was decreased. He was started on $\mathrm{d}$ penicillamine. On Examination child had pallor, icterus, BP - 110/70 mm of Hg, pulse -110/ min regular and good volume. His respiratory rate was 44 / min with signs of distress and stony dull note and reduced air entry on right side of the chest. His abdomen was distended with shiny skin and dilated veins. There was no organomegaly. Shifting dullness was present. Patient was shifted to PICU. On investigations his $\mathrm{Hb}$ was $9.8 \mathrm{gm} / \mathrm{dl}$, TLC-11000/cu mm, SGOT- 140 IU/L, SGPT- 408 IU/L, ALP- $234 \mathrm{IU} / \mathrm{L}$, TSB-32 mg/dl, serum albumin was $2 \mathrm{gm} / \mathrm{dl}$, INR- 1.74. Chest x-ray showed massive right sided pleural effusion. Pleurocentesis was done and $230 \mathrm{ml}$ of fluid was withdrawn which was turbid and showed glucose $48 \mathrm{mg} / \mathrm{dl}$, protein of $5.2 \mathrm{gm} / \mathrm{dl}, \mathrm{LDH}-423 \mathrm{IU} / \mathrm{ml}$, cytology showed plenty of lymphocytes. Pleural fluid ADA was $80 \mathrm{U} / \mathrm{ml}$. On the basis of investigations, child was diagnosed as having tuberculosis and was started on antitubercular drugs. His father was diagnosed as having pulmonary tuberculosis three months back and was on treatment. His abdominal distension slowly increased, and child started having irrelevant talk. His repeat INR was 2.8 and child was managed according to the hepatic failure regimen. Patient further deteriorated on day eight and was ventilated but died on the same day.

\section{Chronic hepatitis and cirrhosis Case 4}

A 14 year old adolescent boy presented with the history of yellowish discolouration of eyes, abdominal pain and distension for four months. There was no history of vomiting, sleep disturbance, malena or haematemesis. There was no history of any blood transfusion. On examination child had pallor, he was icteric, vitals were stable. There was moderate distension and skin over the abdomen was shiny with dilated veins. There was no organomegaly. Fluid thrill was present. Slit lamp examination showed presence of KF ring in both the eyes. His $\mathrm{Hb}$ was $8.8 \mathrm{gm} / \mathrm{dl}$, SGOT-118 IU/L, SGPT-321 IU/L, ALP- 480 IU/L, TSB-12 mg/dl. His 24 hour urinary copper was $1580 \mathrm{mcg}$ and serum ceruloplasmin was $10 \mathrm{mg} / \mathrm{dl}$. Patient was started on tablet lasilactone, multivitamins and $\mathrm{d}$ penicillamine. As patient was vitally stable and abdominal distension has decreased. He was discharged after 10 days of hospital stay. Patient was better on follow-up and his urinary copper decreased significantly, d penicillamine was continued in reduced doses.

\section{Neurological manifestations of Wilson's disease Case 5}

An 8 year old boy was brought to hospital with complaints of yellowish discolouration of eyes for two months. There were no other complaint. On examination child was thinly built. Systemic examination showed icterus and mild pallor. Liver span was $12 \mathrm{~cm}$. Rest systemic examination was normal. On investigation $\mathrm{Hb}$ was $9.8 \mathrm{gm} / \mathrm{dl}$, TSB-5.2 mg/dl with direct component $3 \mathrm{mg} / \mathrm{dl}$, ALP 72 IU/L, SGPT - 113 and SGOT - 204 IU/L. On further investigation bilateral KF ring was present and 24 hour urinary copper was $1234 \mathrm{mcg}$ and serum ceruloplasmin was $16 \mathrm{mg} / \mathrm{dl}$. He was started on d penicillamine and zinc. After one year he again visited hospital with complaints of abnormal movements of left upper and lower limb in the form of choreoathetoid movement. It was associated with right sided upper motor neuron facial palsy. He had dystonia involving again left side only and deep tendon reflexes were brisk. CT scan showed opacities in the gangliocapsular region (Fig 1) and MRI brain revealed bilaterally symmetrical altered signal intensity areas in caudate, lentiform nucleus, and thalamus and midbrain appearing hyperintense on $\mathrm{T} 2$ and 
FLAIR, isointense on T1W1 with few of them showing diffusion restriction on DWI.

Patient was started on trihexyphenidyl and clonazepam and showed improvement after seven days of starting therapy.

\section{Renal Rickets in a case of Wilson's disease Case 6}

An eight year old boy presented with history of knock knees. His X-ray knee showed rachitic changes with marked osteopenia and was treated with multiple courses of megadoses of vitamin D from other health care facility with no response. He also had short stature and there was no rachitic rosary. His renal and liver function tests were normal except alkaline phosphatase which was 502 $\mathrm{IU} / \mathrm{L}$. His parathyroid level was $21 \mathrm{pg} / \mathrm{ml}$ (Reference - 8-53 pg/ml), serum phosphate $3.3 \mathrm{mg} /$ $\mathrm{dl}$ and serum calcium was $8 \mathrm{mg} / \mathrm{dl}$. ABG showed $\mathrm{pH}$ of 7.2 , bicarbonate $16.7 \mathrm{mmol} / \mathrm{l}$, anion gap -10.3. He was thus labeled as renal rickets. He was worked up for Wilson's disease. KF ring was absent on ophthalmic examination, urinary copper was $1578 \mathrm{mcg}$ and serum ceruloplasmin was $10 \mathrm{mg} / \mathrm{dl}$. He was started on d penicillamine and referred to orthopedic department for corrective surgery of knock knees.

\section{Hemolytic Anemia in a case of Wilson's Disease Case 7}

An 11-year-old girl came to casualty with difficulty in breathing and yellowish discoloration of eyes for two days. On arrival to casualty she had gasping breathing with poorly felt pulses. She was immediately intubated and shifted to PICU. On examination her HR was $140 / \mathrm{min}$, BP was $86 / 60$ $\mathrm{mm}$ of $\mathrm{Hg}$. She had severe pallor and icterus. Liver was just palpable and spleen not palpable. Her investigations revealed $\mathrm{Hb} 3.4 \mathrm{gm} / \mathrm{dl}$. Her other cell lines were normal. Her MCV was $102 \mathrm{fl}$ and corrected reticulocyte count was 2.4. Malaria antigen test was negative. LFT showed bilirubin to be $32 \mathrm{mg} / \mathrm{dl}$ out of which unconjugated was 29 $\mathrm{mg} / \mathrm{dl}$. Her liver enzymes were normal. Her coagulation studies were normal. DCT was negative. Considering autoimmune hemolytic anemia, azithromycin was started as mycoplasma pneumoniae is one of the causes for autoimmune Haemolytic anaemia. Being a Coombs negative hemolytic anemia, her urinary copper was sent which was $1645 \mathrm{mcg}$ and serum ceruloplasmin was $15 \mathrm{mg} / \mathrm{dl}$. We were not able to do slit lamp examination in this patient. She was transfused with packed cell volume under steroid cover as immune hemolytic anemia was first on differential diagnosis list. She died on third day of admission because of multiorgan dysfunction syndrome.

\section{Asymptotic cases diagnosed at screening Case 8}

A 3-year-old female toddler was brought to us for screening of Wilson's disease as her elder sibling was a known case of Wilson's disease. She was asymptomatic otherwise. Her Liver function tests revealed SGOT- 75 IU/L, SGPT- $116 \mathrm{IU} / \mathrm{L}$, serum albumin -3 gm/dl, TSB- 3.25 and conjugated-1.71. 24-hour urinary copper was $1245 \mathrm{mcg}$, serum ceruloplasmin was $18 \mathrm{mg} / \mathrm{dl}$ and $\mathrm{KF}$ ring was absent on slit lamp examination. Child was started on d penicillamine and is doing good in follow-up. Her follow-up urinary copper was $549 \mathrm{mcg} / 24$ hour. Zinc was also started and plan is to shift the child to zinc monotherapy later if her liver function test are normal.

\section{Case 9}

One and half year-old toddler boy was screened for Wilson's disease, as his elder brother was suffering from Wilson's disease. His KF ring was absent but urinary copper came out to be $1123 \mathrm{mcg}$. Serum ceruloplasmin was $14 \mathrm{mg} / \mathrm{dl}$. He was started on d penicillamine and zinc. He is yet to be followed up.

\section{DISCUSSION}

Wilson's disease is an inherited disease of copper metabolism with incidence varying from one in $35,000-100,000$ live births across various geographical regions. ${ }^{4}$ Most children with WD present with liver disease followed by neurological manifestations which is more common during adolescence. ${ }^{5}$ The patient usually presents with hepatic involvement which constitute $42 \%$ of cases, $34 \%$ patients have neurological symptoms, $10 \%$ have psychiatric manifestations, $12 \%$ have endocrinal and haematological manifestations and $1 \%$ may have renal involvement. More than one organ involvement may be evident at the time of presentation in as many as $25 \%$ of the patients. ${ }^{6}$ 
Here we report a case series of nine patients out of which two patients were asymptomatic that is $22.3 \%$, five patients had hepatic manifestations accounting for $55.5 \%$, one presented with haemolytic anaemia and one with arthropathy that is $11.11 \%$ each. Out of five patients with hepatic involvement, one presented with neurological manifestations after one year of diagnosis. Though our series had very less patients we had results similar to study by Kliene et al. where 28 children with WD were studied, out of which $42.8 \%$ were asymptomatic, $46.3 \%$ had hepatic involvement and $10.7 \%$ had neurological involvement at the time of presentation. $^{7}$

Hepatic involvement in WD may vary from asymptomatic liver involvement to acute liver failure or cirrhosis. In our case series one patient presented with acute liver failure, four had chronic liver disease out of which two presented with acute deterioration. All our children had low serum ceruloplasmin and increased urinary copper levels which is similar to study by Kini et al. ${ }^{8}$ The accumulation of copper in various organs is the cause of wide range of manifestations in WD. The mutation in ATP7B gene results in accumulation of copper in the liver as copper excretion in the bile through $\mathrm{P}$ type ATPase is defective as a result of this mutation. ${ }^{9}$ As the child approaches second decade there is deposition of copper in other organs like brain, cornea, heart and kidney due to copper overload which occurs over time. If WD is not diagnosed and treated early, the child presents with liver failure or cirrhosis of liver which occurs very rapidly.

In our study one patient presented with difficulty in walking and later diagnosed as renal rickets due to WD. Similar to this case there are case reports where resistant rickets was the sole manifestation of Wilson's disease. ${ }^{10,11}$

One patient in our case series had haemolytic anaemia as a presentation with normal liver function test except the bilirubin level similar to case reports by Santra et al and Xing-Nong Ye et al. ${ }^{12,13}$ Copper deposition on descemet membrane results in $\mathrm{KF}$ ring seen at margins of cornea on slit lamp examination. Many previous studies on WD have shown that KF rings are present in only $44 \%$ to $62 \%$ of patients at the time of diagnosis. ${ }^{14-18} \mathrm{KF}$ ring is almost always present in children with neurological manifestations and absent in those who are asymptomatic at presentation. In our case series three had $\mathrm{KF}$ rings present at the time of diagnosis that constitute $33.33 \%$, slit lamp examination was not possible in two children while it was absent in all the other patients.

The diagnosis of WD is not a problem in children with advanced liver disease provided it is suspected. The diagnostic challenge arises in asymptomatic children, children with mild disease and children with other system manifestations. The diagnostic panel should include liver function test (serum transaminases, alkaline phosphatase, serum bilirubin and prothrombin time), 24-hour urinary copper and serum ceruloplasmin level. Serum ceruloplasmin $<10 \mathrm{mg} / \mathrm{dl}$ establishes the diagnosis of WD but borderline values doesn't exclude the diagnoses and additional tests are needed for confirmation. ${ }^{19}$ The measurement of 24-hour urinary copper help in the diagnosis of WD, the level more than $100 \mathrm{ug} / 24$ hours in children with symptomatic liver disease is considered positive, value more than $40 \mathrm{ug} /$ day may indicate WD and further investigations should be planned. ${ }^{20}$

Ferenci scoring system should be used for the diagnosis of WD as recommended by committee of the European Society for Paediatric Gastroenterology, Hepatology and Nutrition. The scoring system is based on eight parameters (KF ring, neuropsychiatric symptoms of WD or typical MRI findings, Coombs negative haemolytic anaemia + high serum copper, urinary copper, quantitative liver copper assessment after liver biopsy, rhodanine positive hepatocytes if quantitative copper estimation is not possible, detection of disease causing mutation, serum ceruloplasmin). Each parameter is scored ranging from -1 to 4 . If the subtotal of score is between 0 1 WD is unlikely, score between 2 - 3 suggests probable WD and if the score is 4 or more is there is high likelihood of WD. The committee has advised a stepwise diagnostic approach for WD. Step 1 includes clinical evaluation, liver function tests, serum ceruloplasmin and 24 hour urinary copper. In the second step molecular testing for 
common mutations is done. In case molecular testing is inconclusive or not possible, liver biopsy is done in the last step for liver copper estimation. Ferenci score is calculated at each step and if it is four or more the diagnosis is established and treatment is started without moving to the next step. WD should be sought in siblings and parents of confirmed cases. ${ }^{20}$

Treatment for symptomatic WD includes copper chelating agents ( $d$ penicillamine being the most common agent used) along with restriction of copper rich foods. In asymptomatic children identified by family screening, treatment should be started as early as two to three years of age. ${ }^{20} \mathrm{D}$ penicillamine when started timely can prevent the progression of the disease in asymptomatic children. As zinc acetate has a good safety profile it is also advised as monotherapy in asymptomatic children diagnosed through screening though treatment failure has been seen in symptomatic children. ${ }^{21-24}$ However, children with significant liver disease should be treated with copper chelating agents. These children can however be shifted on zinc therapy after the adequate copper levels are achieved monitored by urinary copper levels as long as serum aminase level remains normal. ${ }^{20}$ Children with decompensated liver cirrhosis can be treated with combination of zinc salts and a chelating agent that may preclude the need for a liver transplantation. ${ }^{20}$ However all children with decompensated liver cirrhosis should ideally be managed in paediatric liver transplant centre. The patients with fulminant presentation rarely survive without transplantation. In these patients the removal of free copper can be achieved through molecular absorption recirculating system (MARS) or total plasma exchange (TPE). Both the methods are equally effective and efficiently remove copper but TPE is less costly and more widely available. These methods are not the definitive treatment modalities but can act as a bridge to survival in patients where immediate liver transplantation is not possible. ${ }^{19}$
All WD patients should be closely followed up following the initiation of the therapy and should be monitored by thorough physical examination and laboratory investigations which include LFT, 24-hour urinary copper and serum ceruloplasmin. Follow up ensures the assessment of efficacy, over dosage, or non-adherence to therapy and adverse events. If on follow-up adverse effects of $\mathrm{d}$ penicillamine therapy are seen, it is to be stopped and shift to trientine or zinc depending on the severity of liver disease. Also children on $d$ penicillamine should be monitored for drug induced glomerular injury by doing periodic urinary analysis for proteinuria. ${ }^{19}$ In symptomatic patients once chelation therapy is started follow-up is planned after one month then one to three monthly till remission, and after that child is followed every three to six monthly. ${ }^{20}$ Drugs which can be used in neurowilson's include anticholinergics and baclofen for dystonia, levodopa for parkinsonism, primidone and propanolol for tremors. For rehabilitation, physiotherapy and speech therapy is useful. ${ }^{19}$

\section{CONCLUSIONS}

WD in children should be suspected in every case of unexplained liver involvement and also in patients with extrahepatic manifestations as early institution of available therapy is associated with good overall outcome and also prevents progression of the disease. This case series is an attempt to help the treating paediatrician guide when to suspect WD and how to manage these patients to improve overall prognosis.

\section{REFERENCES}

1. Bandmann O, Weiss KH, Kaler SG. Wilson's disease and other neurological copper disorders. Lancet Neurol 2015;14:103-13. DOI:https://doi.org/10.1016/s1474-4422(14)70190-5 
2. Roberts EA, Schilsky ML. Diagnosis and treatment of Wilson disease: an update. Hepatology. 2008;47:2089-111. DOI:10.1002/hep.22261

3. European Association for Study of Liver. Clinical practice guidelines: Wilson's disease. J Hepatol. 2012;56:67185. DOI:https://doi.org/10.1016/j.jhep.2011.11.007

4. Roberts EA, Schilsky ML. A practical guideline on Wilson's disease. Hepatology. 2003;37:1475-1492. DOI:https:// doi.org/10.1053/jhep.2003.50252

5. Kalra V, Khurana D, Mittal R. Wilson's disease- Early onset and lessons from a pediatric co-hort in India. Indian Pediatr. 2000;37:595- 601. PMID:10869138

6. Sternlieb I and Schienberg IH. Wilson's disease: Diseases of the Liver. In: Schiff L and Schiff ER, editors. Philadelphia: Lippincott Company; 1992. pp. 659-668.

7. Kleine R.T, Mendes R, Pugliese R, Miura I, Danesi V, Porta G et al. Wilson's disease: an analysis of 28 Brazilian children. Clinics. 2012;67(3):231-5. DOI:10.6061/clinics/2012(03)05

8. Kini S, Handattu K, Konda K.C, Bhat R. Clinical profile and outcome of Wilson disease in Indian children: A single centre study. Sri Lanka J Child Health. 2019;48(2):134-9. DOI: http://dx.doi.org/10.4038/sljch.v48i2.8706

9. Reilly M, Daly L, Hutchinson M. An epidemiological study of Wilson's disease in the Republic of Ireland. J Neurol Neurosurg Psychiatry. 1993;56:298-300. DOI: https://dx.doi.org/10.1136\%2Fjnnp.56.3.298

10. Palkar A, Shrivastava M.S ,Padwal N.J ,Padhiyar R.N, Moulick N.Renal tubular acidosis due to Wilson's disease presenting as metabolic bone disease. BMJ Case Reports. 2011;1-4. DOI:10.1136/bcr.04.2011.4121

11. Subrahmanyam DKS, Vadivelan M,Giridharan S, Balamurugan N. Wilson's disease -A rare cause of renal tubular acidosis with metabolic bone disease. Indian J Nephrol. 2014;24(3):171-4. DOI:10.4103/0971-4065.132017

12. Santra G, Paul R, Choudhury PS, Ghosh SK, De D, Das S, et al. Haemolytic anaemia as first manifestation of Wilson's disease: a report of two cases. J Assoc Physicians India. 2014;62(10):55-7. PMID:25906525

13. Xing-Nong Y, Li-Ping M, Yin-Jun L, Hong-Yan T. Hemolytic anemia as first presentation of Wilson's disease with uncommon ATP7B mutation. Int J Clin Exp Med. 2015;8(3):4708-11. PMID:26064408

14. Steindl P, Ferenci P, Dienes HP, Grimm G, Pabinger I, Madl C, et al. Wilson's disease in patients presenting with liver disease: a diagnostic challenge. Gastroenterology. 1997;113:212-218. DOI:https://doi.org/10.1016/ s0016-5085(97)70097-0

15. Gow PJ, Smallwood RA, Angus PW, Smith AL, Wall AJ, Sewell RB, et al. Diagnosis of Wilson's disease: an experience over three decades. Gut. 2000;46:415-9. DOI:https://doi.org/10.1136/gut.46.3.415

16. Emre S, Atillasoy EO, Ozdemir S, Schilsky M, Rathna Varma CV, Thung SN, et al. Orthotopic liver transplantation for Wilson's disease: a single-center experience. Transplantation 2001; 72:1232-1236. DOI:https://doi.org/ 10.1097/00007890-200110150-00008

17. Medici V, Trevisan CP, D'Inca R, Barollo M, Zancan L, Fagiuoli S, et al. Diagnosis and management of Wilson's disease: results of a single center experience. J Clin Gastroenterol. 2006;40:936-41. DOI: 10.1097/01.mcg. 0000225670.91722 .59 .

18. Merle U, Schaefer M, Ferenci P, Stremmel W. Clinical presentation, diagnosis and long-term outcome of Wilson's disease: a cohort study. Gut. 2007;56:115-20. DOI: 10.1136/gut.2005.087262.

19. Nagral A, Sarma MS, Matthai J, Kukkle PL, Devarbhavi H, Sinha S, et al. Wilson's Disease: Clinical Practice Guidelines of the Indian National Association for Study of the Liver, the Indian Society of Pediatric Gastroenterology, Hepatology and Nutrition, and the Movement Disorders Society of India. J Clin Exp Hepatol. 2019 Jan-Feb;9(1):74-98. DOI: 10.1016/j.jceh.2018.08.009.

20. Socha P, Janczyk W, Dhawan A, Baumann U, D'Antiga L. Wilson's Disease in Children: A Position Paper by the Hepatology Committee of the European Society for Paediatric Gastroenterology, Hepatology and Nutrition. J Pediatr Gastroenter. 2018;66:334-44. DOI: 10.1097/MPG.0000000000001787.

21. Wiggelinkhuizen M, Tilanus ME, Bollen CW. Systematic review: clinical efficacy of chelator agents and zinc in the initial treatment of Wilson disease. Aliment Pharmacol Ther. 2009;29:947-58. DOI: 10.1111/j. 1365-2036.2009.03959.x

22. Weiss KH, Gotthardt DN, Klemm D. Zinc monotherapy is not as effective as chelating agents in treatment of Wilson disease. Gastroenterol. 2011;140:1189.1-98. DOI: 10.1053/j.gastro.2010.12.034. 
23. Santiago R, Gottrand F, Debray D. Zinc therapy for Wilson disease in children in French pediatric centers. J Pediatr Gastroenterol Nutr. 2015;61:613-8. DOI: 10.1097/MPG.0000000000000926.

24. Linn FH, Houwen RH, Van Hattum J. Long-term exclusive zinc monotherapy in symptomatic Wilson disease: experience in 17 patients. Hepatology. 2009;50:1442-52. DOI: 10.1002/hep.23182 